\title{
Mediterranean Diet, Inflammatory and Metabolic Biomarkers, and Risk of Alzheimer's Disease
}

\author{
Yian $\mathrm{Gu}^{\mathrm{a}}$, Jose A. Luchsinger ${ }^{\mathrm{a}, \mathrm{b}, \mathrm{c}, \mathrm{d}}$, Yaakov Stern ${ }^{\mathrm{a}, \mathrm{b}, \mathrm{e}}$ and Nikolaos Scarmeas ${ }^{\mathrm{a}, \mathrm{b}, \mathrm{e}, *}$ \\ a Taub Institute for Research of Alzheimer's Disease and the Aging Brain, Columbia University, New York, NY, USA \\ ${ }^{\mathrm{b}}$ Gertrude H. Sergievsky Center, Columbia University, New York, NY, USA \\ ${ }^{\mathrm{c}}$ Department of Epidemiology, Joseph P. Mailman School of Public Health, Columbia University, New York, NY, \\ USA \\ ${ }^{\mathrm{d}}$ Division of General Medicine, Department of Medicine, Columbia University College of Physicians and \\ Surgeons, New York, NY, USA \\ e Department of Neurology, Columbia University College of Physicians and Surgeons, New York, NY, USA
}

Accepted 29 June 2010

\begin{abstract}
We aimed to investigate the association between adherence to the Mediterranean diet (MeDi) and Alzheimer's disease (AD) risk in a prospective study. Specifically, we analyzed reduced inflammation and improved metabolic profile as a potential medium through which the MeDi reduced the risk of AD. During a 4-year follow-up, 118 incident AD cases were identified among the 1219 non-demented elderly (age $\geqslant 65$ ) subjects who provided dietary information and blood samples at baseline. We used high-sensitivity C-reactive protein (hsCRP) as an index of systemic inflammation, and fasting insulin and adiponectin as indexes of metabolic profile. We investigated whether there was a change in the association between MeDi and incident AD risk when the biomarkers were introduced into multivariable adjusted COX models. Better adherence to MeDi was associated with lower level of hsCRP ( $p=0.003$ ), but not fasting insulin or adiponectin. Better adherence to MeDi was significantly associated with lower risk for AD: compared to those in the lowest tertile of MeDi, subjects in the highest tertile had a $34 \%$ less risk of developing $\mathrm{AD}$ (p-for-trend = 0.04). Introduction of the hsCRP, fasting insulin, adiponectin, or combinations of them into the COX model did not change the magnitude of the association between MeDi and incident $\mathrm{AD}$. Ultimately, the favorable association between better adherence to MeDi and lower risk of AD did not seem to be mediated by hsCRP, fasting insulin, or adiponectin. Other aspects of inflammatory and metabolic pathways not captured by these biomarkers, or non-inflammatory or non-metabolic pathways, may be relevant to the MeDi-AD association.
\end{abstract}

Keywords: Adiponectin, Alzheimer's disease, C-reactive protein, cohort studies, epidemiology, insulin, Mediterranean diet

Supplementary data available online: http://dx.doi.org/10.3233/JAD-2010-100897

\section{INTRODUCTION}

The Mediterranean diet (MeDi), due to its correlation with a low morbidity and mortality for many chron-

* Correspondence to: Nikolaos Scarmeas, MD, MS, Columbia University Medical Center, 622 W 168th St., PH 19th floor, New York, NY 10032, USA. Tel.: +1 212342 1350; Fax: +1 212342 1838; E-mail: ns257@ columbia.edu. ic diseases, has been widely recognized as a healthy eating model [1]. In a recent prospective study, we demonstrated that better adherence to the MeDi was associated with lower risk of prevalent $\mathrm{AD}$ [2], incident AD [3,4], incident MCI, or MCI conversion to AD [5]. The results were partially replicated in a French population which demonstrated that better adherence to the MeDi was associated with slower rates of cognitive decline [6]. However, the underlying mechanisms by 
which the MeDi may reduce AD risk are not fully understood. In a previous study we demonstrated that the association between MeDi and AD risk was not mediated through vascular pathways [2], leading us to explore other possible pathways that might be involved.

Two closely related [7] and potentially important mechanisms for AD are inflammation and metabolic abnormalities [8,9]. Interestingly, mounting evidence from both epidemiological and interventional studies has revealed an effect of the MeDi on inflammatory and metabolic biomarkers [10-18]. Therefore, it is conceivable that the protective role of MeDi on $\mathrm{AD}$ might be mediated by these two pathways involving inflammation and metabolic abnormalities.

To our knowledge, whether and to what extent biomarkers of inflammatory and metabolic pathways explain the association between $\mathrm{MeDi}$ and $\mathrm{AD}$ risk has not been formally investigated to date. To address this question, we performed a prospective study to investigate possible change of the association between baseline MeDi and incident AD (which would constitute evidence of mediation) when high-sensitivity CPR (hsCRP; as a biomarker of inflammation [19]), insulin and adiponectin (as biomarkers of metabolic abnormalities [20,21]) were introduced in statistical models. Similar analysis was also performed to examine whether the cross-sectional association between MeDi and baseline cognitive score can be explained by the three biomarkers.

\section{MATERIALS AND METHODS}

\section{Study population}

The initial sample for this study included 2,778 participants from a prospective study of aging and dementia in Medicare-eligible northern Manhattan residents, age 65 years and older (Washington/Hamilton HeightsInwood Columbia Aging Project II: WHICAP II). The WHICAP II cohort represents a combination of continuing members of the cohort originally recruited in 1992 (WHICAP I; $n=604$ ) and members of a new cohort recruited between 1999 and 2001 ( $n=2,174)$. Both cohorts used similar sampling, assessments and study procedures, which have been described in detail elsewhere [2-5,22-24]. Briefly, at entry, a physician elicited each subject's medical and neurological history and conducted a standardized physical and neurological examination. Each subject also underwent a structured in-person interview including an assessment of health and function and a neuropsychological battery [25]. Subjects were followed at intervals of approximately 1.5 years, repeating the baseline examination and consensus diagnosis [2-5,22-24].

Among the original 2,778 subjects, 345 were excluded due to prevalent dementia, 538 were excluded due to lack of follow-up, and 543 were excluded due to lack of a frozen blood sample. Thus, hsCRP, fasting insulin and adiponectin were measured for the remaining 1,352 subjects in 2008 using frozen blood samples obtained in the WHICAP II baseline examination during 1999-2001. The time of the blood collection was set as the baseline for this study. An additional 113 subjects were excluded because they did not have dietary information available and 12 subjects were excluded due to incomplete dietary information preventing a MeDi calculation. A total of 8 subjects who developed incident dementia other than AD during follow-up were further excluded from the analysis. Thus, the initial analytic sample for both the cross-sectional and the survival analyses comprised 1219 subjects.

Recruitment, informed consent, and study procedures were approved by the Institutional Review Boards of Columbia Presbyterian Medical Center and Columbia University Health Sciences and the New York State Psychiatric Institute.

\section{Diet and MeDi score}

Dietary data regarding average food consumption over the year before the baseline assessment were obtained using a 61-item version of Willett's semi-quantitative food frequency questionnaire (SFFQ) (Channing Laboratory, Cambridge, MA) [26]. Diet information was available at baseline, the same date as blood samples were collected, for 1,099 individuals ( $90.2 \%$ of all subjects in this study). When dietary information was not available on the same visit as the baseline, the diet information closest to the baseline was used. Thus, a total of 98 subjects with diet after blood collection (on average 2.5 years, $\mathrm{SD}=1.1$ year, after blood donation) and 22 with diet before blood collection (on average 6.3 years, $\mathrm{SD}=2.1$ year, before blood donation) were used. We reported the results based on all 1,219 subjects, because 1) we have previously showed the stability of MeDi over a period of 8 years [3,4], and 2) we repeated analyses based on the 1,099 subjects whose diet information and blood samples were collected at the same time, and the results were unchanged (data not shown). The validity (using two 7-day food records) and reliability (using 
two 3-month frequency assessments) of various components of the SFFQ in WHICAP have been previously reported [22-24].

We followed the most commonly described method [27] to construct the MeDi score as described in our previous reports [2-5]. Individuals were assigned a value of 1 for each beneficial component (fruits, vegetables, legumes, cereals, and fish) whose caloric-adjusted consumption was at or above the gender-specific median, for each detrimental component (meat and dairy products) whose caloric-adjusted consumption was below the gender-specific median, for a ratio of monounsaturated fats to saturated fats above the median, and for mild to moderate alcohol consumption $(>0$ to $<$ $30 \mathrm{~g} / \mathrm{d}$ ). The MeDi score was generated for each participant by adding the scores in the food categories (theoretically ranging 0-9) with higher score indicating better adherence to the MeDi.

\section{Cognitive performance at baseline}

A composite cognitive Z-score was developed to summarize cognitive performance as previously described [28-32]. Briefly, we used factor analysis with principal axis factoring and oblique rotation on $15 \mathrm{neu}-$ ropsychological test score variables [25] which grouped cognitive performance into four factors: memory, language, processing speed, and visual-spatial ability. Using cognitive test data from all WHICAP participants at their initial visit, Z-scores for each of the cognitive measures that comprised each factor were created and then averaged to create a composite score for each factor. These factor domain scores were then averaged to derive a composite cognitive Z-score. A higher Z-score indicates better cognitive performance.

\section{Alzheimer's disease diagnosis}

The process for diagnosing $\mathrm{AD}$ patients has been previously reported [2-5]. Briefly, a consensus diagnosis for the presence or absence of dementia was made at a diagnostic conference of neurologists and neuropsychologists. Evidence of cognitive deficit (based on the neuropsychological scores), and evidence of cognitive and social-occupational function decline as compared to the past were the criteria used for the diagnosis of dementia as required by the DSM-III-R. For the diagnosis of probable or possible $\mathrm{AD}$, the criteria of the NINCDS-ADRDA were used. Dietary or biomarker data were not available to the consensus panel and were not considered in the diagnostic process.

\section{Biomarker measurement}

Baseline plasma hsCRP level was measured using ELISA (Diagnostic systems laboratories, INC, Webster, Texas). The assay sensitivity was $1.6 \mathrm{ng} / \mathrm{ml}$, the intra-assay and inter-assay coefficient of variations (CVs) were $4.6 \%$ and $11.7 \%$, respectively. Baseline serum fasting insulin levels were measured using a solid-phase chemiluminescent enzyme immunoassay (Immulite, Diagnostic Products, Los Angeles, CA). The intra-assay and inter-assay CVs were $4.7 \%$ and $8.2 \%$, respectively. Baseline serum total adiponectin levels were measured using radioimmunoassay (Linco Research, Inc, St. Charles, MO). The intra-assay CV was from $1.78 \%$ to $6.21 \%$, and the inter-assay CV was from $6.90 \%$ to $9.25 \%$. Laboratory personnel were blinded as to the dietary data and disease status of the subjects.

\section{Covariates}

Age (years), education (years), caloric intake (kcal), and body mass index (weight in kilograms divided by height in square meters $\left[\mathrm{kg} / \mathrm{m}^{2}\right]$ ) were used as continuous variables. We also considered gender (men as reference), smoking status at baseline evaluation (current smoker at baseline vs. non-smoker), and ethnic groups (non-Hispanic Black, Hispanic, non-Hispanic White or Other). Apolipoprotein E (APOE) genotype was used as a dichotomous variable: absence of versus presence of either 1 or $2 \varepsilon 4$ alleles. A modified version [4] of the Charlson Index of Comorbidity [33] (referred to as 'comorbidity index') was included as a continuous variable.

\section{Statistical analysis}

Characteristics of the subjects

Circulating levels of hsCRP, fasting insulin, and adiponectin had a skewed distribution and were transformed to their natural logarithm. Characteristics of patients, levels of biomarkers, and MeDi tertiles (MeDi score $0-3$ as the lowest, $4-5$ as the middle, and 6-9 as the highest tertile) were compared between $\mathrm{AD}$ cases and dementia-free participants using t-test for continuous variables, and chi-square test for categorical variables. Characteristics of patients were also compared according to the tertiles of MeDi using linear regression models for continuous variables, and chi-square test for categorical variables. Spearman correlation was run to examine the relationship between the $3 \log$-transformed biomarkers. 
Associations between the biomarkers and MeDi score

To test the associations between the biomarkers and MeDi score, linear regression models were used with tertiles of the MeDi score used as an ordinal independent variable to test the linear trend.

\section{Cross-sectional data analysis}

To test the associations between the biomarkers and baseline cognitive score, linear regression models, both unadjusted and adjusted for social-demographic covariates, including age, gender, race, and education, were used. Tertiles of the biomarkers were used as an ordinal independent variable to test the linear trend.

Similar regression analysis adjusted for age, gender, race, and education was also done to examine the association between MeDi and cognitive score.

To test whether biomarkers mediate the association between MeDi and cognitive performance, we evaluated the change of $\beta$ coefficient of MeDi when the biomarkers were added to the regression model adjusted for age, gender, race, and education. Changes of the $\beta$ coefficient values of greater than $15 \%$ were considered evidence of mediation by the variable added to the model [34].

\section{Longitudinal data analysis}

To test the association between the biomarkers and $\mathrm{AD}$ risk, $\mathrm{COX}$ proportional hazards models were used with $\mathrm{AD}$ treated as the dichotomous outcome. Biomarkers were treated as independent variables which were entered into the models in tertiles. Tests for trend with two-sided p-values were evaluated by entering the tertile terms as an ordinal variable in the COX model. The time-to-event variable was time from recording of baseline to incident $\mathrm{AD}$ diagnosis for incident patients; or to the time of the last follow-up for subjects who did not develop dementia.

Similarly, we fit a COX model (original model), adjusted for age, gender, race, and education in the model, to estimate the association between MeDi and AD risk. The main predictor was MeDi score as a continuous variable initially and in tertiles form subsequently. The coefficient of MeDi was denoted as $\beta_{t}$.

Finally, we tested whether the association between MeDi and AD was mediated i) through inflammatory pathway by including hsCRP (model 1); ii) through metabolic pathways by including fasting insulin (model 2), adiponectin (model 3) or both (model 4); or iii) through both inflammatory and metabolic pathways by simultaneously including all three biomarkers (model 5) into the original COX model. The coefficient of
MeDi from all these 5 models is denoted as $\beta_{i}, i=$ $1-5$.

The percentage of the association of MeDi and AD that was mediated through either inflammation, or metabolic factors, or both, was calculated as $\Delta \beta \%=$ $100 \times\left(\beta_{t}-\beta_{i}\right) / \beta_{t}, i=1-5$. In order to maintain consistent sample size in the analysis so that $\beta$ coefficients of different models can be compared appropriately, we excluded 1) censored cases before the earliest event in a stratum that were automatically excluded in COX models; and 2) subjects missing values of covariates or biomarkers.

We performed a supplementary analysis by additionally adjusted for body mass index (BMI), smoking status, alcohol drinking, caloric intake, medical comorbidity index, and $A P O E$ genotype in the COX models. The results were essentially unchanged (data not presented in the current report).

All analyses were performed using PASW Statistics 17.0 (formerly SPSS Inc., Chicago, IL USA). Significance level was set at 0.05 .

\section{RESULTS}

\section{Missing data analysis}

Compared with subjects included in the analysis ( $n=1219)$, subjects who were excluded from the analyses $(n=1559)$ were slightly older (76.7 vs. 79.2 years; $p<0.0001$ ), had lower education (10.5 vs. 9.4 years; $p<0.0001$ ), and more medical comorbidities (1.9 vs. $2.2 ; p<0.0001)$; were less likely to be smokers $(12 \%$ vs. $9 \%, p=0.002)$ and White ( White $31 \%$, Black 30\%, Hispanic 37\%, Other $2 \%$ vs. White $24 \%$, Black 34\%, Hispanic 41\%, Other $1 \%$; $p<0.0001$ ); and were more likely to be APOE $\varepsilon 4$ carriers ( 25 vs. $31 ; p=0.01)$.

\section{Characteristics of subjects}

During an average follow-up of 3.8 (SD, 1.3; range $=1.1 \sim 6.6$ ) years, a total of 118 incident $\mathrm{AD}$ cases were identified. Compared with subjects remaining dementia-free during the follow-up, incident AD cases were older, less educated, and had lower BMIs, were most likely Hispanics (and less likely Whites) (Table 1). AD cases tended to have higher median level of fasting insulin than non-dementia subjects $(p=0.05)$. Compared to subjects in the lowest tertile of MeDi, those in the highest MeDi tertile were more likely to be non- 
Table 1

Demographic, clinical, and dietary characteristics for subjects with Alzheimer's disease and non-demented subjects

\begin{tabular}{|c|c|c|c|c|}
\hline Characteristics & $\begin{array}{c}\text { All } \\
(n=1,219)\end{array}$ & $\begin{array}{c}\text { Demented-free } \\
(n=1,101)\end{array}$ & $\begin{array}{l}\text { Incident AD } \\
(n=118)\end{array}$ & $\mathrm{p}^{*}$ \\
\hline Mean age, year (SD) & $76.7(6.4)$ & $76.3(6.3)$ & $80.7(6.9)$ & $<0.0001$ \\
\hline Female gender, n $(\%)$ & $812(66.6)$ & $736(66.8)$ & $76(64.4)$ & 0.59 \\
\hline Mean education, year $(\mathrm{SD})^{+}$ & $10.50(4.7)$ & $10.85(4.5)$ & $7.23(5.1)$ & $<0.0001$ \\
\hline Race, $\mathrm{n}(\%)$ & & & & $<0.0001$ \\
\hline White & $382(31.3)$ & $365(33.2)$ & $17(14.4)$ & \\
\hline Black & $359(29.5)$ & $326(29.6)$ & $33(28.0)$ & \\
\hline Hispanic & $457(37.5)$ & $390(35.4)$ & $67(56.8)$ & \\
\hline Other & $21(1.7)$ & $20(1.8)$ & $1(0.8)$ & \\
\hline Presence of $A P O E \varepsilon 4$ allele, $\mathrm{n}(\%)^{+}$ & $300(25.1)$ & $275(25.4)$ & $25(21.6)$ & 0.36 \\
\hline Smoker at baseline, $\mathrm{n}(\%)$ & $152(12.5)$ & $134(12.1)$ & $18(15.3)$ & 0.34 \\
\hline Mean medical comorbidity index (SD) & $1.84(1.4)$ & $1.85(1.4)$ & $1.74(1.4)$ & 0.38 \\
\hline Mean caloric intake, Kcal/day (SD) & $1499(560)$ & $1490(552)$ & $1585(630)$ & 0.08 \\
\hline Mean BMI, $\mathrm{Kg} / \mathrm{m}^{2}(\mathrm{SD}){ }^{+}$ & $27.7(5.5)$ & $27.8(5.4)$ & $26.3(5.8)$ & $<0.01$ \\
\hline Mean MeDi (SD) & $4.34(1.7)$ & $4.37(1.7)$ & $4.07(1.8)$ & 0.07 \\
\hline Tertiles of MeDi & & & & 0.09 \\
\hline Low, n $(\%)$ & $400(32.8)$ & $351(31.9)$ & $49(41.5)$ & \\
\hline Middle, n (\%) & $500(41.0)$ & $460(41.8)$ & $40(33.9)$ & \\
\hline High, $\mathrm{n}(\%)$ & $319(26.2)$ & $290(26.3)$ & $29(24.6)$ & \\
\hline Median hsCRP, mg/L(inter-quartile) & $5.5(2.8-14.0)$ & $5.4(2.8-14.0)$ & $5.9(1.9-14.7)$ & 0.57 \\
\hline Median fasting insulin, mIU/ml (inter-quartile) & $8.6(3.0-19.9)$ & $8.3(3.0-19.7)$ & $10.8(3.0-25.5)$ & 0.05 \\
\hline Median adiponectin, $\mu \mathrm{g} / \mathrm{ml}$ (inter-quartile) & $11.1(7.0-18.0)$ & $11.3(7.0-18.0)$ & $10.2(6.8-18.5)$ & 0.75 \\
\hline
\end{tabular}

${ }^{*} \mathrm{p}$ values were from $\chi^{2}$ test for categorical variables, or one-way ANOVA test for continuous variables except for hsCRP, insulin, and adiponectin for which the p values were from Kruskal-Wallis test.

+2 subjects missed information on education. ${ }^{+} 22$ subjects missed information on APOE $\varepsilon 4 .+4$ subjects had missing information on BMI.

smokers, Hispanics (and less likely Black) (Table 2). The three biomarkers were correlated with each other: Spearman correlation coefficient between hsCRP and insulin was 0.14 , between hsCRP and adiponectin -0.12 , and between insulin and adiponectin -0.28 , all $p<0.0001$.

\section{Associations between MeDi and biomarkers}

Compared to the lowest tertile of $\mathrm{MeDi}$, subjects in the highest MeDi tertile tended to have lower level of hsCRP (medians $4.6 \mathrm{mg} / \mathrm{L}$ vs. $6.7 \mathrm{mg} / \mathrm{L}$, p for trend $=0.003$ ). There was no difference between MeDi tertiles regarding fasting insulin or adiponectin levels (Table 2).

\section{Cross-sectional analysis}

Lower cognitive score, indicating worse cognitive performance, was observed among subjects with higher level of hsCRP ( $p=0.01)$ or insulin $(p=0.001)$, or with lower level of adiponectin $(p<0.001)$ (Supplementary Table 1; available online:http://www.j-alz.com /issues/22/vol22-2.html\#supplementarydata03), but the associations were attenuated and no longer significant after adjusting for age, gender, race, cohort, and education (Supplementary Table 1).
Better adherence to the MeDi was marginally associated with significantly better cognitive performance at baseline: after adjusting for age, gender, race, and education, $\beta=0.013$ ( $p=0.05$ ) for each unit increase of MeDi score (Supplementary Table 2). When levels of hsCRP, fasting insulin and adiponectin were, individually or together, added to the original model, the association between MeDi and cognitive performance were essentially the same, with the changes in $\beta$ coefficient of MeDi less than 15\% (Supplementary Table 2).

\section{Longitudinal analysis}

There was no difference between $\mathrm{AD}$ cases and dementia-free subjects in hsCRP, fasting insulin or adiponectin level (Table 1), and the biomarkers were not associated with AD risk in COX models ( $\mathrm{p}$ for trend $=0.68$ for hsCRP, 0.08 for fasting insulin, and 0.06 for adiponectin in unadjusted models; $\mathrm{p}$ for trend $=$ 0.78 for hsCRP, 0.40 for fasting insulin, and 0.66 for adiponectin in models adjusted for age, gender, education, race).

As expected [3,4], better adherence to the MeDi tended to be associated with significantly lower risk for AD: after adjusting for age, gender, race, and education, compared to subjects in the lowest tertile of MeDi score, HR $(95 \% \mathrm{CI})$ for subjects in the highest tertile 
Table 2

Demographic and clinical characteristics by Mediterranean diet score tertiles

\begin{tabular}{|c|c|c|c|c|}
\hline Characteristics & $\begin{array}{c}\text { Low } \\
(N=400)\end{array}$ & $\begin{array}{c}\text { Middle } \\
(N=500)\end{array}$ & $\begin{array}{c}\text { High } \\
(N=319)\end{array}$ & $\mathrm{p}^{*}$ \\
\hline MeDi score & $0-3$ & $4-5$ & $6-9$ & / \\
\hline Mean age, year (SD) & $76.4(6.6)$ & $76.6(6.4)$ & $77.2(6.2)$ & 0.30 \\
\hline Female gender, n (\%) & $268(67)$ & $329(66)$ & $215(67)$ & 0.88 \\
\hline Mean education, year $(\mathrm{SD})^{+}$ & $10.6(4.5)$ & $10.6(4.7)$ & $10.2(5.0)$ & 0.51 \\
\hline Race, n (\%) & & & & 0.007 \\
\hline White & $135(33.8)$ & $150(30.0)$ & $97(30.4)$ & \\
\hline Black & $140(35.0)$ & $139(27.8)$ & $80(25.1)$ & \\
\hline Hispanic & $119(29.8)$ & $202(40.4)$ & $136(42.6)$ & \\
\hline Other & $6(1.5)$ & $9(1.8)$ & $6(1.9)$ & \\
\hline Presence of $A P O E \varepsilon 4$ allele, $\mathrm{n}(\%)^{+}$ & $98(24.9)$ & $117(24.1)$ & $85(26.7)$ & 0.70 \\
\hline Smoker at baseline, $\mathrm{n}(\%)$ & $70(18)$ & $63(13)$ & $19(6.0)$ & $<0.0001$ \\
\hline Mean medical comorbidity index (SD) & $1.8(1.4)$ & $1.9(1.4)$ & $1.8(1.4)$ & 0.94 \\
\hline Mean caloric intake, Kcal/day (SD) & $1509(631)$ & $1501(534)$ & $1485(506)$ & 0.85 \\
\hline Mean BMI, $\mathrm{Kg} / \mathrm{m}^{2}(\mathrm{SD})^{+}$ & $27.9(5.8)$ & $27.7(5.2)$ & $27.4(5.4)$ & 0.45 \\
\hline Incident $\mathrm{AD}, \mathrm{n}(\%)$ & $49(12)$ & $40(8)$ & $29(9)$ & 0.09 \\
\hline Median hsCRP, mg/L(inter-quartile) & $6.7(3.5-17.0)$ & $5.6(2.8-13.4)$ & $4.6(2.4-13.7)$ & 0.003 \\
\hline Median fasting insulin, mIU/ml (inter-quartile) & $8.2(3.0-20.5)$ & $9.0(3.0-22.5)$ & $8.1(3.0-17.7)$ & 0.50 \\
\hline Median adiponectin, $\mu \mathrm{g} / \mathrm{mL}$ (inter-quartile) & $11.6(7.1-18.3)$ & $11.1(6.8-17.9)$ & $11.0(6.9-17.9)$ & 0.32 \\
\hline
\end{tabular}

was 0.66 (0.41-1.04) after multivariable adjustment, $\mathrm{p}$ for trend $=0.04$. Additional adjusting for other factors (including APOE4, comorbidity, smoking status, caloric intake, and $\mathrm{BMI})$, the results were essentially the same: the HR $(95 \% \mathrm{CI})$ comparing subjects in the highest tertile to the lowest was $0.66(0.41-1.06)$, p for trend $=0.06$.

Qualifications for mediators in general require associations of the potential mediator with both the independent variable (MeDi in this case) and the outcome (AD risk in this case) [35]. Based on the above presented results, we expected there would be no mediating effect by hsCRP, fasting insulin and adiponectin. Nevertheless, we decided to proceed with the mediation analyses because of (i) the association of some of the biomarkers with MeDi and (ii) the strong evidence from the literature regarding associations between inflammatory and metabolic biomarkers with both $\mathrm{AD}$ and the MeDi adherence [7-18]. When levels of hsCRP, fasting insulin and adiponectin were, individually or together, added to the original model, the HRs did not change (Table 3 ). The changes in $\beta$ coefficient from the original model to the 5 models were all less than $15 \%$ (Table 3 ).

\section{DISCUSSION}

In this prospective study, hsCRP, fasting insulin and adiponectin did not mediate the association between
MeDi and AD risk. These results suggest that better adherence to MeDi might not be associated with reduced risk for $\mathrm{AD}$ via inflammatory or metabolic pathways.

Inflammation factors have been found to be associated with a higher risk for AD and cognitive decline [8]. Two large-scaled prospective studies showed baseline blood levels of inflammatory markers are associated with higher risk of incident AD [36,37]. Although plasma hsCRP was not associated with risk of incident AD in the present study, it was inversely associated with baseline cognitive score (Supplementary Table 2), especially in the memory and visual-spatial domains as previously reported [32]. At the same time, several intervention studies found that adherence to MeDi may affect blood levels of inflammatory biomarkers [10,11, 18]. In the present study, median hsCRP level was about $30 \%$ lower among subjects adhering to the highest compared to the lowest tertile of the MeDi, a magnitude similar to those reported by other studies [12, 13]. Despite these, we found that hsCRP was not able to explain a meaningful proportion of the association between MeDi and either cognitive performance or risk for incident $\mathrm{AD}$, indicating that elevated hsCRP level (possibly related to dietary behavior) might not mediate the diet-AD association.

We also hypothesized that the association between MeDi and AD could be mediated via fasting insulin and adiponectin. On the one hand, association be- 
Table 3

Hazard ratios for subjects with Alzheimer disease and non-demented subjects by Mediterranean diet score in continuous and tertile form adjusted for hsCRP, fasting insulin or adiponectin*

\begin{tabular}{|c|c|c|c|c|c|}
\hline Model $^{+}$ & MeDi & HR $(95 \% \mathrm{CI})$ & $\beta(\Delta \beta \%)^{\#}$ & $\mathrm{p}$ & p-trend \\
\hline original model & $\begin{array}{c}\text { MeDi continuous } \\
\text { MeDi tertile } \\
\text { Low } \\
\text { Middle } \\
\text { High }\end{array}$ & $\begin{array}{c}0.87(0.78-0.97) \\
1 \text { (reference) } \\
0.57(0.37-0.88) \\
0.66(0.41-1.04)\end{array}$ & $\begin{array}{l}-0.559 \\
-0.420\end{array}$ & $\begin{array}{l}0.01 \\
0.08\end{array}$ & 0.04 \\
\hline $\begin{array}{l}\text { Model } 1 \\
\text { (original model }+ \text { hsCRP) }\end{array}$ & $\begin{array}{c}\text { MeDi continuous } \\
\text { MeDi tertile } \\
\text { Low } \\
\text { Middle } \\
\text { High }\end{array}$ & $\begin{array}{c}0.87(0.78-0.97) \\
1 \text { (reference) } \\
0.57(0.37-0.88) \\
0.66(0.41-1.06)\end{array}$ & $\begin{array}{l}-0.145(-1.3 \%) \\
-0.558(0.2 \%) \\
-0.413(1.7 \%)\end{array}$ & $\begin{array}{l}0.01 \\
0.08\end{array}$ & 0.05 \\
\hline $\begin{array}{l}\text { Model } 2 \\
\text { (original model }+ \text { insulin) }\end{array}$ & $\begin{array}{c}\text { MeDi continuous } \\
\text { MeDi tertile } \\
\text { Low } \\
\text { Middle } \\
\text { High }\end{array}$ & $\begin{array}{c}0.87(0.77-0.97) \\
1 \text { (reference) } \\
0.56(0.37-0.87) \\
0.66(0.41-1.04)\end{array}$ & $\begin{array}{l}-0.574(-2.7 \%) \\
-0.419(0.2 \%)\end{array}$ & $\begin{array}{l}0.01 \\
0.08\end{array}$ & 0.05 \\
\hline $\begin{array}{l}\text { Model } 3 \\
\text { (original model }+ \text { adiponectin) }\end{array}$ & $\begin{array}{c}\text { MeDi continuous } \\
\text { MeDi tertile } \\
\text { Low } \\
\text { Middle } \\
\text { High }\end{array}$ & $\begin{array}{c}0.87(0.78-0.97) \\
1 \text { (reference) } \\
0.57(0.37-0.88) \\
0.67(0.42-1.07)\end{array}$ & $\begin{array}{c}-0.138(3.4 \%) \\
-0.559(0 \%) \\
-0.400(4.8 \%)\end{array}$ & $\begin{array}{l}0.01 \\
0.09\end{array}$ & 0.06 \\
\hline $\begin{array}{l}\text { Model } 4 \\
\text { (original model }+ \text { insulin }+ \text { adiponectin) }\end{array}$ & $\begin{array}{c}\text { MeDi continuous } \\
\text { MeDi tertile } \\
\text { Low } \\
\text { Middle } \\
\text { High }\end{array}$ & $\begin{array}{c}0.87(0.79-0.97) \\
1 \text { (reference) } \\
0.56(0.36-0.86) \\
0.67(0.42-1.07)\end{array}$ & $\begin{array}{c}-0.140(2.1 \%) \\
-0.582(-4.1 \%) \\
-0.399(5.0 \%)\end{array}$ & $\begin{array}{l}0.01 \\
0.09\end{array}$ & 0.06 \\
\hline $\begin{array}{l}\text { Model } 5 \\
\text { (original model }+ \text { all biomarkers) }\end{array}$ & $\begin{array}{c}\text { MeDi continuous } \\
\text { MeDi tertile } \\
\text { Low } \\
\text { Middle } \\
\text { High }\end{array}$ & $\begin{array}{c}0.87(0.78-0.97) \\
1 \text { (reference) } \\
0.56(0.36-0.86) \\
0.68(0.42-1.08)\end{array}$ & $\begin{array}{l}-0.140(2.1 \%) \\
-0.581(-3 \%) \\
-0.391(6.9 \%)\end{array}$ & $\begin{array}{l}0.01 \\
0.10\end{array}$ & 0.06 \\
\hline
\end{tabular}

*All models limit to 1202 subjects without missing values on hsCRP, fasting insulin or adiponectin. Total number of incident AD cases were 118 for all models in this table.

\# The $\Delta \beta \%$ for each tertile was calculated as compared to the corresponding tertile in the original model.

+ Original model: adjusted for age, gender, education and race.

Model 1, 2, and 3: same as the original model, with additional adjustment for hsCRP, fasting insulin, and adiponectin level, respectively.

Model 4: same as the original model, with additional adjustment for fasting insulin and adiponectin levels.

Model 5: same as the original model, with additional simultaneous adjustment for hsCRP, fasting insulin and adiponectin levels.

tween metabolic abnormalities and risk of AD has been demonstrated in multiple cohorts $[9,38]$. In our study, fasting insulin tended to be inversely associated with cognitive score and $\mathrm{AD}$ cases tended to have higher median level of fasting insulin than non-dementia subjects, although insulin was not associated with risk of $\mathrm{AD}$ in the survival analysis adjusted for demographic covariates. Adiponectin was neither associated with baseline cognitive score nor associated with AD risk after adjusting for demographic covariates. On the other hand, there are intervention studies reporting significant reductions in serum insulin in groups assigned to MeDi $[10,16]$, and cross-sectional studies reporting MeDi-like dietary patterns $[14,17]$ positively associat- ed with adiponectin levels. However, the association between MeDi and fasting insulin and adiponectin was not always consistent, as one intervention study failed to show a change of serum insulin level after 1-year of MeDi-type intervention [39], and no intervention study has been done on the association between MeDi and adiponectin. Nevertheless, in the current study, neither fasting insulin nor adiponectin was associated with MeDi, which might partly explain the finding that neither of the two biomarkers was able to explain a meaningful proportion of the association between MeDi and AD, or the association between MeDi and baseline cognitive score. Therefore, it seems that the potential mediating role of fasting insulin and adiponectin needs to be 
further explored only when more consistent evidence are available supporting the existence of an association between MeDi with fasting insulin and adiponectin.

Other potential explanations for the null results of our study include that hsCRP may not capture the full inflammation pathway, and fasting insulin and adiponectin may not fully capture all the related metabolic changes. For example, one study found increased levels of $\alpha 1$-antichymotrypsin ( $\alpha 1$-ACT) along with occasional detection of interleukin-6 (IL-6) might be peripheral markers of the "acute reaction" in the brain, while hsCRP was not [40]. In a prospective study in Rotterdam, high levels of $\alpha 1$-ACT and IL-6 were associated with an increased risk of dementia to a higher extent than hsCRP [37].

Alternatively, other biological mechanisms may be responsible for the MeDi-AD association. Growing evidence implicates oxidative damage in the pathogenesis of AD [41]. The MeDi contains high concentrations of complex phenols and other substances with antioxidant properties (such as vitamins $\mathrm{C}$, vitamins $\mathrm{E}$, and carotenoids), and may reduce markers of oxidative stress such as isoprostanes [42]. Therefore, the MeDi could be capturing the composite influence of dietary antioxidants and this could, at least partially, explain the association with a lower risk of AD. Similarly, vascular variables are also likely to be in the causal pathway between MeDi and AD considering the strong evidence relating the MeDi to lower risk of vascular risk factors [43], which may contribute to increased risk of AD [44]. Although our previous study using clinical diagnosis of vascular diseases as vascular variables did not suggest these variables as a potential mediators for the association between MeDi and AD risk [2], other more sensitive measurement of vascular events, such as subclinical vascular change in magnetic resonance imaging, need to be considered in future studies.

The study has limitations. It lacks repeated measurement for hsCRP, insulin, and adiponectin. However, it has been shown that circulating levels of hsCRP [45], insulin [46], and adiponectin [46] are quite stable within individuals over a period of 3 years. Another limitation of the study was that the inflammatory and metabolic pathways may not be fully captured since other biomarkers of these two pathways were not measured. Participants with loss of follow-up or lack of blood samples were different from the remaining participants with regard to some AD risk factors. Although we adjusted for all the above factors in our models, excluding these subjects may have introduced selection bias. A common limitation of studies of diet and disease is misclassification of exposure due to limited accuracy in assessing diet using SFFQ. In prospective studies, though, exposure measurement error can usually be assumed to be nondifferential with respect to disease status or to covariates used to adjust the multivariate risk for $\mathrm{AD}$, so the measurement error may actually bias the magnitude of the association toward null [47]. Similarly, the possibility of disease misclassification bias may not be completely ruled out, despite the use of standard criteria, the diagnostic expertise of our center, and the thorough workup.

Our study is innovative in exploring the potential mechanisms of the association between MeDi and AD risk by examining the mediating role of inflammatory and metabolic biomarkers in this relationship. The study is prospective in design, thus limiting the possibility of reverse causality to a great extent. Furthermore, our previous reports of the same study population have performed a series of sensitivity analyses by either adjusting baseline Clinical Dementia Rating score or excluding subjects with mild cognitive deficits at baseline and with less than 2 years of follow-up, and the association between MeDi and risk of $\mathrm{AD}$ did not change materially, suggesting that, although we cannot completely exclude it, it is less likely that the degree of adherence to MeDi was affected by early, subclinical dementia process $[3,4]$. Dietary data were collected with a previously validated instrument that has been used widely in epidemiological studies [48]. The diagnosis of AD took place in a university hospital with expertise in dementia and was based on comprehensive assessment and standard research criteria. Information about various potential AD risk factors has been carefully collected, recorded, and adjusted for in the analyses. The study is community-based and the population is multiethnic, increasing the external validity of the findings.

In summary, the lower risk of $\mathrm{AD}$ associated with better adherence to MeDi observed in this study population does not seem to be mediated by hsCRP, fasting insulin or adiponectin, suggesting that better adherence to MeDi might not reduce risk for $\mathrm{AD}$ via inflammatory or metabolic pathways, or that the used biomarkers do not fully capture the corresponding pathways.

\section{ACKNOWLEDGMENTS}

Federal NIA grants P01-AG07232 and AG028506; Alzheimer's Association grant IIRG-09-133014.

Authors' disclosures available online (http://www.jalz.com/disclosures/view.php?id=519). 


\section{REFERENCES}

[1] Roman B, Carta L, Martinez-Gonzalez MA, Serra-Majem L (2008) Effectiveness of the Mediterranean diet in the elderly. Clin Interv Aging 3, 97-109.

[2] Scarmeas N, Stern Y, Mayeux R, Luchsinger JA (2006) Mediterranean diet, Alzheimer disease, and vascular mediation. Arch Neurol 63, 1709-1717.

[3] Scarmeas N, Luchsinger JA, Schupf N, Brickman AM, Cosentino S, Tang MX, Stern Y (2009) Physical activity, diet, and risk of Alzheimer disease. JAMA 302, 627-637.

[4] Scarmeas N, Stern Y, Tang MX, Mayeux R, Luchsinger JA (2006) Mediterranean diet and risk for Alzheimer's disease. Ann Neurol 59, 912-921.

[5] Scarmeas N, Stern Y, Mayeux R, Manly JJ, Schupf N, Luchsinger JA (2009) Mediterranean diet and mild cognitive impairment. Arch Neurol 66, 216-225.

[6] Feart C, Samieri C, Rondeau V, Amieva H, Portet F, Dartigues JF, Scarmeas N, Barberger-Gateau P (2009) Adherence to a Mediterranean diet, cognitive decline, and risk of dementia. JAMA 302, 638-648.

[7] Haffner SM (2003) Insulin resistance, inflammation, and the prediabetic state. Am J Cardiol 92, 18J-26J.

[8] Akiyama H, Barger S, Barnum S, Bradt B, Bauer J, Cole GM, Cooper NR, Eikelenboom P, Emmerling M, Fiebich BL, Finch CE, Frautschy S, Griffin WS, Hampel H, Hull M, Landreth G, Lue L, Mrak R, Mackenzie IR, McGeer PL, O'Banion MK, Pachter J, Pasinetti G, Plata-Salaman C, Rogers J, Rydel R, Shen Y, Streit W, Strohmeyer R, Tooyoma I, Van Muiswinkel FL, Veerhuis R, Walker D, Webster S, Wegrzyniak B, Wenk G, Wyss-Coray T (2000) Inflammation and Alzheimer's disease. Neurobiol Aging 21, 383-421.

[9] Luchsinger JA, Tang MX, Shea S, Mayeux R (2004) Hyperinsulinemia and risk of Alzheimer disease. Neurology 63, 11871192.

[10] Esposito K, Marfella R, Ciotola M, Di Palo C, Giugliano F, Giugliano G, D'Armiento M, D'Andrea F, Giugliano D (2004) Effect of a Mediterranean-Style Diet on Endothelial Dysfunction and Markers of Vascular Inflammation in the Metabolic Syndrome: A Randomized Trial. JAMA 292, 1440-1446.

[11] Estruch R, Martinez-Gonzalez MA, Corella D, Salas-Salvado J, Ruiz-Gutierrez V, Covas MI, Fiol M, Gomez-Gracia E, Lopez-Sabater MC, Vinyoles E, Aros F, Conde M, Lahoz C, Lapetra J, Saez G, Ros E (2006) Effects of a Mediterraneanstyle diet on cardiovascular risk factors: a randomized trial. Ann Intern Med 145, 1-11.

[12] Chrysohoou C, Panagiotakos DB, Pitsavos C, Das UN, Stefanadis C (2004) Adherence to the Mediterranean diet attenuates inflammation and coagulation process in healthy adults: The ATTICA Study. J Am Coll Cardiol 44, 152-158.

[13] Fung TT, McCullough ML, Newby P, Manson JE, Meigs JB, Rifai N, Willett WC, Hu FB (2005) Diet-quality scores and plasma concentrations of markers of inflammation and endothelial dysfunction. Am J Clin Nutr 82, 163-173.

[14] Fragopoulou E, Panagiotakos DB, Pitsavos C, Tampourlou M, Chrysohoou C, Nomikos T, Antonopoulou S, Stefanadis C (2009) The association between adherence to the Mediterranean diet and adiponectin levels among healthy adults: the ATTICA study. J Nutr Biochem 21, 285-289.

[15] Mantzoros CS, Williams CJ, Manson JE, Meigs JB, Hu FB (2006) Adherence to the Mediterranean dietary pattern is positively associated with plasma adiponectin concentrations in diabetic women. Am J Clin Nutr 84, 328-335.
[16] Jula A, Marniemi J, Huupponen R, Virtanen A, Rastas M, Ronnemaa T (2002) Effects of diet and simvastatin on serum lipids, insulin, and antioxidants in hypercholesterolemic men: a randomized controlled trial. JAMA 287, 598-605.

[17] Yannakoulia M, Yiannakouris N, Melistas L, Kontogianni MD, Malagaris I, Mantzoros CS (2008) A dietary pattern characterized by high consumption of whole-grain cereals and lowfat dairy products and low consumption of refined cereals is positively associated with plasma adiponectin levels in healthy women. Metabolism 57, 824-830.

[18] Mena MP, Sacanella E, Vazquez-Agell M, Morales M, Fito M, Escoda R, Serrano-Martinez M, Salas-Salvado J, Benages N, Casas R, Lamuela-Raventos RM, Masanes F, Ros E, Estruch $R$ (2009) Inhibition of circulating immune cell activation: a molecular antiinflammatory effect of the Mediterranean diet. Am J Clin Nutr 89, 248-256.

[19] Ridker PM, Morrow DA (2003) C-reactive protein, inflammation, and coronary risk. Cardiol Clin 21, 315-325.

[20] Laakso M (1993) How good a marker is insulin level for insulin resistance? Am J Epidemiol 137, 959-965.

[21] Trujillo ME, Scherer PE (2005) Adiponectin-journey from an adipocyte secretory protein to biomarker of the metabolic syndrome. J Intern Med 257, 167-175.

[22] Luchsinger JA, Tang MX, Shea S, Mayeux R (2002) Caloric intake and the risk of Alzheimer disease. Arch Neurol 59, 1258-1263.

[23] Luchsinger JA, Tang MX, Shea S, Mayeux R (2003) Antioxidant vitamin intake and risk of Alzheimer disease. Arch Neurol 60, 203-208.

[24] Luchsinger JA, Tang MX, Siddiqui M, Shea S, Mayeux R (2004) Alcohol intake and risk of dementia. J Am Geriatr Soc 52, 540-546.

[25] Stern Y, Andrews H, Pittman J, Sano M, Tatemichi T, Lantigua R, Mayeux R (1992) Diagnosis of dementia in a heterogeneous population. Development of a neuropsychological paradigmbased diagnosis of dementia and quantified correction for the effects of education. Arch Neurol 49, 453-460.

[26] Willett WC, Sampson L, Stampfer MJ, Rosner B, Bain C, Witschi J, Hennekens CH, Speizer FE (1985) Reproducibility and validity of a semiquantitative food frequency questionnaire. Am J Epidemiol 122, 51-65.

[27] Trichopoulou A, Costacou T, Bamia C, Trichopoulos D (2003) Adherence to a Mediterranean diet and survival in a Greek population. N Engl J Med 348, 2599-2608.

[28] Manly JJ, Bell-McGinty S, Tang MX, Schupf N, Stern Y, Mayeux R (2005) Implementing diagnostic criteria and estimating frequency of mild cognitive impairment in an urban community. Arch Neurol 62, 1739-1746.

[29] Manly JJ, Tang MX, Schupf N, Stern Y, Vonsattel JP, Mayeux R (2008) Frequency and course of mild cognitive impairment in a multiethnic community. Ann Neurol 63, 494-506.

[30] Siedlecki KL, Honig LS, Stern Y (2008) Exploring the structure of a neuropsychological battery across healthy elders and those with questionable dementia and Alzheimer's disease. Neuropsychology 22, 400-411.

[31] Scarmeas N, Albert SM, Manly JJ, Stern Y (2006) Education and rates of cognitive decline in incident Alzheimer's disease. J Neurol Neurosurg Psychiatry 77, 308-316.

[32] Noble JM, Manly JJ, Schupf N, Tang MX, Mayeux R, Luchsinger JA (2010) Association of C-reactive protein with cognitive impairment. Arch Neurol 67, 87-92.

[33] Charlson ME, Pompei P, Ales KL, MacKenzie CR (1987) A new method of classifying prognostic comorbidity in longitu- 
dinal studies: development and validation. J Chronic Dis 40 373-383.

[34] Hosmer DW, Lemeshow S (1999) Interpretation of a fitted proportional hazards regression model; Multiple-covariate models In Applied survival analysis: regression modeling of time to event data John Wiley and Sons, Inc., New York, pp. 129137.

[35] MacKinnon DP, Lockwood CM, Hoffman JM, West SG, Sheets V (2002) A comparison of methods to test mediation and other intervening variable effects. Psychol Methods 7, 83104.

[36] Schmidt R, Schmidt H, Curb JD, Masaki K, White LR, Launer LJ (2002) Early inflammation and dementia: a 25-year followup of the Honolulu-Asia Aging Study. Ann Neurol 52, 168174.

[37] Engelhart MJ, Geerlings MI, Meijer J, Kiliaan A, Ruitenberg A, van Swieten JC, Stijnen T, Hofman A, Witteman JC, Breteler MM (2004) Inflammatory proteins in plasma and the risk of dementia: the rotterdam study. Arch Neurol 61, 668-672.

[38] Kopf D, Frolich L (2009) Risk of incident Alzheimer's disease in diabetic patients: a systematic review of prospective trials. J Alzheimers Dis 16, 677-685.

[39] Michalsen A, Lehmann N, Pithan C, Knoblauch NT, Moebus S, Kannenberg F, Binder L, Budde T, Dobos GJ (2006) Mediterranean diet has no effect on markers of inflammation and metabolic risk factors in patients with coronary artery disease. Eur J Clin Nutr 60, 478-485.

[40] Licastro F, Morini MC, Polazzi E, Davis LJ (1995) Increased serum alpha 1-antichymotrypsin in patients with probable Alzheimer's disease: an acute phase reactant without the peripheral acute phase response. J Neuroimmunol 57, 71-75.

[41] Pratico D (2002) Alzheimer's disease and oxygen radicals: new insights. Biochem Pharmacol 63, 563-567.

[42] Sanchez-Moreno C, Cano MP, de Ancos B, Plaza L, Olmedilla B, Granado F, Martin A (2006) Mediterranean vegetable soup consumption increases plasma vitamin $\mathrm{C}$ and decreases F2-isoprostanes, prostaglandin E2 and monocyte chemotactic protein-1 in healthy humans. J Nutr Biochem 17, 183-189.

[43] Singh RB, Dubnov G, Niaz MA, Ghosh S, Singh R, Rastogi SS, Manor O, Pella D, Berry EM (2002) Effect of an IndoMediterranean diet on progression of coronary artery disease in high risk patients (Indo-Mediterranean Diet Heart Study): a randomised single-blind trial. Lancet 360, 1455-1461.

[44] Breteler MM (2000) Vascular risk factors for Alzheimer's disease: an epidemiologic perspective. Neurobiol Aging 21, 153160.

[45] Gu Y, Zeleniuch-Jacquotte A, Linkov F, Koenig KL, Liu M, Velikokhatnaya L, Shore RE, Marrangoni A, Toniolo P, Lokshin AE, Arslan AA (2009) Reproducibility of serum cytokines and growth factors. Cytokine 45, 44-49.

[46] Kaplan RC, Ho GY, Xue X, Rajpathak S, Cushman M, Rohan TE, Strickler HD, Scherer PE, Anastos K (2007) Withinindividual stability of obesity-related biomarkers among women. Cancer Epidemiol Biomarkers Prev 16, 1291-1293.

[47] Schatzkin A, Subar AF, Moore S, Park Y, Potischman N, Thompson FE, Leitzmann M, Hollenbeck A, Morrissey KG, Kipnis V (2009) Observational epidemiologic studies of nutrition and cancer: the next generation (with better observation). Cancer Epidemiol Biomarkers Prev 18, 1026-1032.

[48] Willett W, Lenart E (1998) Reproducibility and Validity of Food-Frequency Questionnaires In Nutritional Epidemiology, Willett W, ed. Oxford University Press, New York, pp. 101147. 